OECD/ITF Joint Transport Research Centre Discussion Papers $2008 / 02$

\title{
The Design of Effective Regulations of Transport
}

\section{Winston Harrington}




\section{\OEC

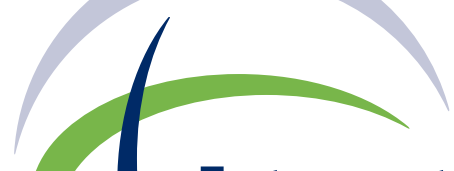 \\ International Transport \\ JOINT TRANSPORT RESEARCH CENTRE}

Forum

\section{Discussion Paper N0. 2008-Z January 2008}

\section{The Design of Effective Regulations of Transport}

Winston HARRINGTON

Resources for the Future Washington, DC, USA 
The views expressed in this paper are those of the authors and do not necessarily represent positions of the Resources for the Future, the OECD

or the International Transport Forum. 
TABLE OF CONTENTS

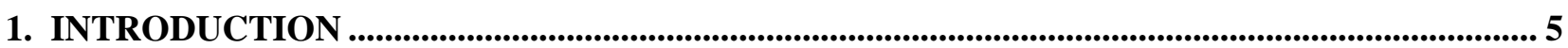

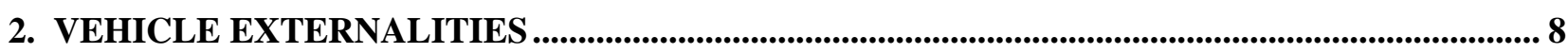

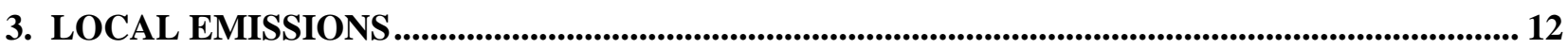

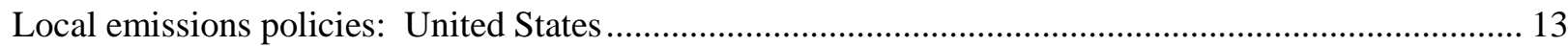

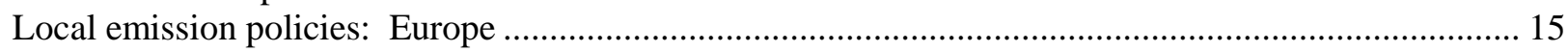

4. GLOBAL EMISSIONS ....................................................................................................................... 17

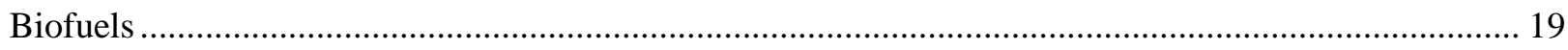

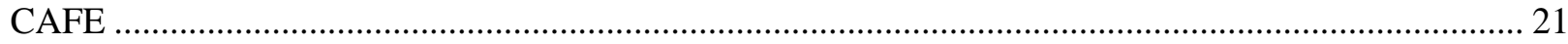

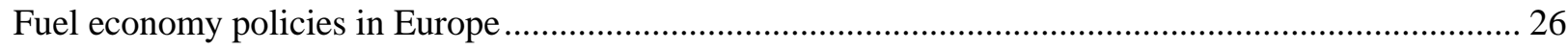

5. THE COST OF FUEL-ECONOMY STANDARDS: PROBLEMS OF OBSERVATION ............ 27

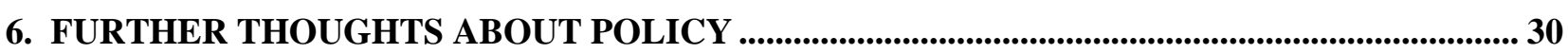

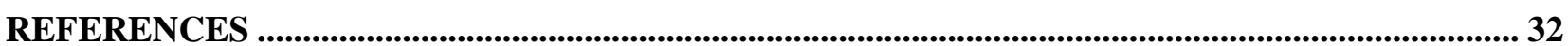





\section{INTRODUCTION}

Motor vehicles have been recognized as an important contributor to air quality problems for over 40 years, almost as long as air pollution itself has been considered a public health problem instead of simply a nuisance. Attempts to control mobile emissions began in the United States, Japan and northern Europe around 1970, amid growing concerns about unhealthy air. Until about a decade ago, direct public health impacts were the focus of auto emissions policies, which were designed to reduce emissions of the so-called "conventional" pollutants carbon monoxide (CO), volatile organic compounds (VOCs), and oxides of nitrogen (NOx), and lead, substances that either alone or upon reaction with other pollutants can cause respiratory disease, elevated cardiovascular disease risk, high blood pressure, photochemical smog formation, reduced visibility, and acid deposition. Of these, the most serious (and fortunately the easiest to deal with) was lead, an additive that raised octane levels in gasoline. Today, gasoline is lead-free in most of the developed world and is being steadily phased out almost everywhere else.

More recently, these local air quality concerns were joined by a newly emerging problem for which vehicles are a major contributor -- global warming. Motor vehicles emit a substantial share of global $\mathrm{CO}_{2}$, including roughly 32 percent of total US emissions. ${ }^{1}$ Although the policy response so far has been very limited, many knowledgeable observers believe that implementation of more vigorous $\mathrm{CO}_{2}$ policies, especially in developed countries, is only a matter of time.

This paper will trace the development of modern regulation of emissions, both local and global, from motor vehicles. To illuminate the principal themes of this story the focus will be on the experiences of the United States and Europe. Among those themes, three stand out, questions that sooner or later must be considered in the development of any environmental policy.

First, the theme of federalism. In every country, governments are constituted at various levels of aggregation, from local to national. Which level of government is the most suitable for attacking a given public problem. If different levels of government can fairly claim to have a role in addressing the problem, how will the various responsibilities be assigned and coordinated? In order to develop an effective and efficient public policy, the governments must have both the right incentives and the capacity to do so.

Finding the right level of government to address an environmental problem is a tradeoff between two competing considerations. The government's jurisdiction must be large enough to "internalize the externalities," as an economist would say. That is, if either the environmental evil or the policy remedy has effects that extend beyond its borders, then the policy-maker's incentives will very likely be inappropriate. For example, policies to control emissions of stationary-source air pollutants may not be stringent enough if most of the effects of pollution are experienced in

\footnotetext{
${ }^{1}$ Source: The U.S. Greenhouse Gas Inventory. USEPA 430-R-05-003. April, 2005.
} 
neighboring jurisdictions. At the same time, the level of government must be appropriate to the problem. Smaller, more local units of government are more likely to know the preferences of their citizens, yet less likely to have the expertise and experience to deal effectively with particular problems.

The second pervasive theme here is the choice of policy instrument: the specific mechanisms used to achieve the environmental objective. It is common to pose two polar types: direct regulation and economic incentives (EI). Rather than commands or requirements, EI instruments provide penalties or rewards to encourage behavior that will improve environmental quality. Another way of putting the difference is this: With direct regulation, there is a bright line that determines whether behavior will be tolerated. With EI, the relationship between performance and consequences is continuous and gradual. There is no bright line, just steadily increasing rewards for better performance.

Direct regulation and EI approaches can be compared in many ways; for an extensive discussion, see Harrington, Morgenstern and Sterner (2004). Here the focus will be on a couple of distinctions that are particularly telling for motor vehicle policies and that are prominent in the discussion below. Most importantly, EI are generally more cost-effective, in that at the same cost of a regulatory instrument, they deliver more environmental improvement. A less well-known advantage of EI is that more information is revealed to policy-makers about the actual cost of regulation, both before and after the regulation is imposed. Under direct regulation, such cost information is rarely forthcoming and is often available only from the parties being regulated, who have little incentive to be truthful. On the other side there were fears, especially among regulators or environmentalists, that the greater flexibility and discretion granted to polluters by EI approaches would compromise their effectiveness. In addition, direct regulation was seen as more straightforward and simpler. EI required either introduction of taxes, usually beyond the jurisdiction of environmental authorities, or the construction of novel, artificial markets in pollutant reductions.

Thus, despite these apparent advantages, until about fifteen years ago the novelty of EI approaches and the distrust of regulators ensured that the environmental policies actually chosen were heavily dominated by direct regulation. This observation is especially true in the United States, where a great volume of new federal regulation to promote environmental quality was enacted during the 1970s, none of which could be characterized as economic incentives. Since then, however, there has been a remarkable surge of interest in EI approaches in environmental policy. Since at least 1995, whenever new environmental policies are proposed, economic incentive instruments have frequently been proposed and have generally received a respectful hearing.

Instrument choice is about more than just rewards, penalties and requirements, however. It is also about which activities should be rewarded or penalized and how and where performance is to be measured. The most economically efficient instrument must penalize, and therefore be able to measure, the activity by an economic agent that directly causes the damages. For motor vehicles it would be ideal to place a fee on vehicle emission rates or accumulated vehicle emissions directly, and even better if the fee rate varied by time and place, since the impact of emissions depends on circumstances. Such fees operate on every relevant margin: the number of vehicles, how much they are driven, how drivers drive them and how much of the emissions produced are 
captured by the emission control systems. Thus, vehicle manufacturers would have the appropriate incentive to reduce the emission rates of their vehicles; refiners would have an appropriate incentive to produce fuels that minimize emissions; and motorists would experience directly in their pocketbooks the emission consequences of their driving and trip-taking behaviors and alter them accordingly. In addition, such a tax instrument would operate on all vehicles on the road, whereas the policies that are actually implemented tend to affect only new vehicles.

However, measuring emissions of vehicles in use in a practical manner is not technically feasible for some pollutants, notably the conventional pollutants NOx, VOCs, $\mathrm{CO}$ and particulates. This was true in the early 1970s when emission regulations were first appearing, and it is still true today. A second-best alternative would be to use periodic emission tests to estimate emission rates together with mileage to estimate emissions. As discussed further below, though, policymakers have avoided this approach. In most jurisdictions the primary regulatory instrument to control conventional pollutants is a maximum standard on the emission rates of new vehicles.

For the main global pollutant, $\mathrm{CO}_{2}$, matters are very different. The amount of $\mathrm{CO}_{2}$ generated is determined almost exactly by the amount of carbon in the fuel. The amount of $\mathrm{CO}_{2}$ discharged is the same as the amount generated, as $\mathrm{CO}_{2}$ abatement is technically infeasible in vehicles. Thus, measurement of carbon used (or, if all fuels have the same carbon content, the measurement of fuel used) is the proper performance measure for this pollutant. Despite this, regulation of global pollutants from vehicles is frequently an emission rate regulation.

The third theme is policy interactions. Local and global air pollution are not the only social problems associated with motor vehicle use. Traffic congestion, accidents, and oil dependency are also matters of concern and, to various degrees, grist for the policy mill. In addition, of course, government policies at different levels can also interact. Typically, legislative and regulatory initiatives have dealt with environmental, safety and other externality issues in isolation, without considering their effect on other vehicle-related concerns. The question is, how important are these interactions? Do policies interacted to deal with one have an appreciable adverse effect on others? Are opportunities for jointly effective policies being missed?

Fourth, economic considerations, including the costs of compliance, the direct and indirect burden of those costs, their effects on regulatory stringency, and through these mechanisms, their political consequences, will be considered. The "cost" of something is a deceptively difficult concept and rarely more so than when dealing with the costs of environmental regulations, which can rarely be directly observed. Not surprisingly, the estimated ex ante costs of regulations usually have greater influence on events than estimates of actual costs made after the regulation has been implemented. Therefore, the accuracy of these cost estimates is an important public policy consideration and partially justifies consideration of policy instruments where cost information is revealed automatically. 


\section{VEHICLE EXTERNALITIES}

Many observers have tried to quantify the external costs of motor vehicle use, and these efforts have been fairly controversial. For one thing, industry advocates and conservative commentators often complain that the calculations are unfair because the leave out the benefits of vehicle use. Therefore, before turning to the external costs of auto use, let us consider the private benefitsand costs - of vehicle use. Not only will this digression help explain why vehicle benefits seem to be neglected in policy discussions, but it will help put the valuation of the externalities in perspective. First, we note that the private cost of owning and using a vehicle is high-so high, in fact, that vehicular transportation now accounts for $18 \%$ of expenditures among American households (BLS 2001). According to the American Automobile Association, the per-mile cost of driving is about $56 \phi / \mathrm{mile}$. AAA assumes the vehicle is an average new car, and $73 \%$ of the costs are fixed (depreciation, insurance and financing), leaving an average variable costs of vehicle use to be around $15 \not$ per mile. Barring a major drop in fuel prices, these variable costs will in all likelihood increase with vehicle age, as maintenance expenses increase and the vehicle passes out of warranty. In Europe, the costs of vehicle use are even higher than in the U.S., owing to higher fuel and vehicle prices. On either side of the ocean, then, vehicle ownership and use is obviously a very costly proposition.

Despite the high costs, driving remains the principal mode of household transportation, in Europe almost as much as in the United States. This is illustrated in Table 1, which shows the mode split between passenger cars and ground transit (rail or bus) in the United States and selected EU countries. As expected, the U.S. tops the chart at $96 \%$ passenger cars. But the Netherlands, United Kingdom and Norway are not far behind at $87 \%$, and the only country in the table at less than $75 \%$ is the recently-added Czech Republic.

Table 1 also shows total vehicle ownership per 1000 of population in these countries, both in the year 2002 and at "saturation." The saturation estimates were developed by Dargay et al. (2007), who show that country vehicle ownership rates depend very strongly and robustly on per-capita income. The relationship is S-shaped: at very low and very high income levels, car ownership grows slowly. In the former case the slow growth reflects not only the low population of potential buyers, but perhaps also the lack of infrastructure (roads, fueling stations etc.) to support vehicle ownership. But as income grows, it seems, everyone wants a car. 


\begin{tabular}{|c|c|c|c|}
\hline \multicolumn{4}{|c|}{$\begin{array}{c}\text { Table } 1 \\
\text { Indicators of car use }\end{array}$} \\
\hline & \multirow{2}{*}{$\begin{array}{l}\text { Mode split: motor vehicle } \\
\text { vs. bus or rail transit }\end{array}$} & \multicolumn{2}{|c|}{ Vehicle ownership } \\
\hline & & 2002 & Saturation \\
\hline United States & 96 & 812 & 852 \\
\hline Netherlands & 87 & 477 & 613 \\
\hline United Kingdom & 87 & 515 & 707 \\
\hline Norway & 87 & 521 & 852 \\
\hline Sweden & 83 & 500 & 825 \\
\hline Switzerland & 78 & 559 & 803 \\
\hline Czech Republic & 70 & 390 & 819 \\
\hline
\end{tabular}

The saturation level depends on population density and degree of urbanization, and for most European countries the estimate is above 700 vehicles per 1000 population. It should also be noted that comparable saturation rates apply in developing countries as well. The vehicle fleet in China, for example, is predicted to grow from its current 16 vehicles per 1000 population to 807 . This estimate is much higher than others for developing countries, but the strong tie to income is reasonably persuasive.

The high level of vehicle ownership, together with the high cost of ownership can only mean one thing: the private benefits of vehicle ownership is very high indeed. All the evidence suggests that the desire for convenient, on-demand private personal transport is universal and, once it becomes affordable, irresistible. Its main urban alternative, bus and rail transit, is competitive for work trips to the urban core, but for other types of trips, it is simply less convenient, unless population densities are very high. And again, for any trip by car its marginal benefits must exceed its marginal costs; otherwise the trip would not be made. These marginal costs will of course be highly variable, but the average variable operating costs, estimated above to be about $15 \varnothing$ per mile, are a reasonable lower bound. ${ }^{2}$

To come back to the main point, motor vehicles do provide large benefits to the users. However, these benefits are private benefits, and nearly anyone can obtain them if he is willing to pay for them. There may be some public benefits to motor vehicle use, but few come to mind. The external effects of motor vehicle use - those that fall on nonusers-are almost exclusively bad, and they are not easy to avoid. In particular there are few markets where those affected can take private actions to eliminate their exposure to these externalities. If there is to be a response to auto externalities, it has to be collective.

The main vehicle externalities are shown in Table 2. Columns 2 and 3 of this table give the upper and lower bounds save one of a set of externality studies primarily from the gray literature. The

\footnotetext{
${ }^{2}$ This estimate only counts the costs of vehicle use. The cost of elapsed time to the driver and other occupants of the vehicle is ignored.
} 
estimates reflect many studies and it is often not clear what the assumptions are underlying the estimate. This accounts for the broad range in cost estimates. The fourth column gives results from a more selective set, mostly from published economics articles, where it's clear what the assumptions are.

To allow externalities to be compared with one another, it is necessary to express them in common or at least convertible units, and it is most natural to express them in terms that are consistent with indicators of vehicle use. The most common indicator of vehicle use is vehicle miles/kilometers traveled (VMT or VKT).It is important to keep in mind, however, that this is a unit of convenience and may obscure the enormous variation in these estimates of external costs. It is very misleading to suppose that, say, $x$ miles of driving activity always produce $y$ in damages. The enormous range in estimates may become clearer following an explanation of how each of the external cost estimates in the table below are calculated.

Conventional pollutants. The externality is generated by emissions, mostly from the tailpipe. To get from emissions to damages, one must estimate the effect of the emissions on air quality, the effect of air quality on health, and then value the change in health endpoints. The marginal effect of emissions on air quality is difficult to estimate quantitatively and depends critically on location, and the there is rarely good data on actual vehicle emissions anyway. Even in this case, it is heroic to assume a fixed relationship between miles driven and damages, since that relationship will depend on the vintage of the vehicle and its abatement equipment as well as the time and place the vehicle is driven. Likewise, the effect of air quality on health depends on population density, the age distribution, personal habits and time spent outside, and existing dose-response functions are subject to large uncertainties. The degree of uncertainty is enormous in the valuation step as well.

Global pollutants. For a given type of fuel, the principal greenhouse gas of interest, $\mathrm{CO}_{2}$ is produced in fixed proportions to the carbon in the fuel consumed, because there is no technology on the horizon that will enable $\mathrm{CO}_{2}$ abatement technology on the vehicle. Also, all units of $\mathrm{CO}_{2}$ emitted are safely assumed to have the same climate consequences. Therefore, the relevant margin for estimating $\mathrm{CO}_{2}$ damages is fuel consumption, or better, carbon content of fuel consumed. It is a little more complicated if biofuels are involved, because the only carbon that should be counted is that in that in the fossil fuel used in its production. When the carbon use estimates are converted to per-mile units, as in Table 2, additional assumptions are required about the average fuel economy of all vehicles. Still, getting from vehicle use to GHG emissions is subject to much less uncertainty than is the case for conventional pollutants. However, converting GHG emission estimates to estimates of changes in climate, and the valuation of the climate changes, is extremely uncertain.

Congestion. In the table below congestion costs (chiefly lost time, but in principle anyway, also the annoyance of driving in stop-and-go traffic and the uncertainty in estimating arrival times) are estimated a 5-6.5ф per mile. The lower number is taken from a Federal Highway Administration Capacity study. The upper number was calculated at RFF as follows. First, total travel time for one day for all motorists in a metropolitan area (Washington, DC in this case) is estimated using a simulation model of local travel behavior. This is compared to what the travel time would be if the cost if travel were slightly reduced and the total travel increased. This procedure gives the change in welfare that would accompany a small increase in total vehicle use in Washington, DC. The estimate is extrapolated to other American cities using the ratio of total travel demand in 
those cities to the available highway capacity. The per-unit congestion cost is determined by dividing the sum of congestion costs in all cities with populations exceeding 100,000 by the total estimated VMT in the nation for one weekday.

This procedure calculates congestion costs at the margin, but it also tacitly assumes no congestion on non-urban highways. While congestion is likely to be lower on such roads, it is not zero. Therefore it is likely that the estimate is low, notwithstanding the fact that it is higher than other unit estimates of congestion costs. A larger point is that the representation of congestion costs on this unit cost basis is especially problematic, since it is likely that there is an inverse relationship between the length of a trip and the congestion experienced by or caused by the traveler. But it is useful as a static number for comparison purposes.

Accidents. The entries in the table should refer only to external costs of accidents; injuries or property damages incurred by the driver should be excluded. They definitely are excluded for the studies supporting column 4, but some studies in the broader collection represented in columns 2 and 3 may refer to all accident damages, internal or external. Compared to estimation of emission damages, accident damages are relatively straightforward. There is good accident data, at least when fatalities are involved, and those accidents probably represent the large majority of economic damages from accidents. Valuing the health effects of accidents is no more difficult than valuation of health effects of pollution.

Energy security. Energy security is now a particular concern for both the U.S. and the EU, especially in transportation, with its high level of oil use. Dependency on oil imports from potentially hostile sources (the Middle East and Russia) is said to be a problem for at least three reasons: price volatility, price manipulation, and implications for national security. For none of these reasons is the case for externality airtight, however. Oil prices are volatile, to be sure, and economies can be damaged by volatility in oil prices. However, it is not clear that a marginal reduction in U.S. or EU reliance on imports can affect the volatility. Oil is fungible, and a supply disruption anywhere from any cause will unsettle markets everywhere, regardless of the dependency level. The national-security justification is questionable because defense expenditures are unlikely to be marginal. Perhaps the most important national security concern is the flow of petrodollars into terrorist organizations, but in this case the problem is not the level of oil imports, but the level of imports from hostile countries that tolerate such organizations. 


\begin{tabular}{|c|c|c|c|}
\hline \multicolumn{4}{|c|}{$\begin{array}{c}\text { Table } 2 . \\
\text { Range of Reported External Costs in Cost-of-Driving Studies } \\
\text { (Cents per Mile) }\end{array}$} \\
\hline & $\operatorname{Low}^{\mathrm{a}}$ & $\mathrm{High}^{\mathrm{a}}$ & $\mathrm{JEL}^{\mathrm{c}}$ \\
\hline Air pollution & 1 & 14 & 2.3 \\
\hline Climate change & 0.3 & 1.1 & $0.3-3.5$ \\
\hline Congestion & 4 & 15 & $5-6.5$ \\
\hline Accidents (external) & 1 & 10 & $2-7$ \\
\hline Energy security & 1.5 & 2.6 & $0-2.2$ \\
\hline \multicolumn{4}{|c|}{$\begin{array}{l}\text { a'Harrington and McConnell (2003). Combination of the studies surveyed by K.T. } \\
\text { Analytics (1997) and Gomez-Ibanez (1997). " "Low" and "high" are respectively the } \\
\text { second lowest and the second highest estimates reported in the articles surveyed. } \\
{ }^{\mathrm{c}} \text { Based on a survey of the economics literature. See Parry, Walls and Harrington (2006) } \\
\text { and citations therein for further discussion. }\end{array}$} \\
\hline
\end{tabular}

Comparing the estimates, it appears the most economically significant externalities are congestion and accidents. However, they are also the ones that are most familiar. Almost everyone has experienced congestion first-hand and most have some experience with accidents as well. Even in the worst case, congestion and accidents will affect us individually or in small groups. In contrast, energy supply disruption or significant climate change will affect everyone if they occur, and the possibility, especially for climate change, of disruption on a national or global scale cannot be dismissed. In other words, the mean values of these large-scale externalities perhaps should be tempered by keeping in mind the variances, which are virtually unknowable.

\section{LOCAL EMISSIONS}

Since 1970, when the modern environmental movement was in its infancy, the principal approach to reducing emissions from motor vehicles has been emission standards for new vehicles, in units of mass per unit distance. Describing these vehicle policies, which developed rather differently in the U.S. and Europe but have ended up close to the same place, is the main purpose of this section. In addition, extensive regulations have been adopted governing fuel quality, with the twin purposes of (i) reducing the quantity and toxicity of fuel constituents that, when used in vehicles, cause environmental quality problems directly and (ii) ensuring coordination with new vehicle regulations, which often required fuels with particular qualities. While the fuel stories are interesting and instructive, they are not included in this review.

Other policies for control of local emissions have been developed, including vehicle inspection and maintenance $(\mathrm{I} / \mathrm{M})$, vehicle scrappage, and no-driving days. Some of these policies have seemed to be rather cost-effective in some local applications, but all have suffered from a difficulty in determining what their true emission reductions are. In any case, the emission 
reductions from these policies are small relative to the reductions brought about by the vehicle emission standards. They will not be considered further here.

\section{Local emissions policies: United States}

Before 1970 air quality, to the extent that it entered public policy at all, was primarily under the jurisdiction of the states and, except for California, had nothing to do with motor vehicles. The federal government's role was limited to research and financial support. The centralization of environmental policymaking is primarily the result of a series of landmark statutes that were passed between 1969 and 1980. ${ }^{3}$ It is not clear that these centralizing moves were part of a grand plan; rather it appears to have been prompted by more ad hoc concerns. First, there were some environmental problems that crossed state lines. More importantly, there was an air of crisis at the time, a concern that environmental problems had to be dealt with right away. Most of the states had, in the minds of many, demonstrated that they could not act quickly enough or forcefully enough to deal with the multitude of environmental problems facing the country. It was said that the federal government was the only level of government powerful enough to stand up to the large corporations that were presumably the primary source of environmental degradation. In particular, federal authority over environmental policy would avoid the much-feared "race to the bottom" - polluters' shopping around for lenient states willing to sacrifice environmental quality for new jobs and economic growth.

For air quality the national policy was set in the Clean Air Act of 1970, which mandated the setting of uniform ambient standards, plus a set of technology-based regulations for new sources, both stationary and mobile. The states' role was to do what needed to be done over and above the federal technology regulations to meet the ambient standards. These standards were initially supposed to be met in 1975, although the deadline was almost immediately pushed back to 1977. After almost 40 years, this remains the basic approach to air quality planning. Although the air is a lot cleaner today, the ambient standards have still not been met, largely because the ambient standards have been tightened significantly and new pollutants have emerged as problems. The task has proved to be a much bigger and more complicated job than originally anticipated.

California was the only state that had established emission reductions before 1970 for new cars. It retained this under the new Clean Air Act and indeed its vehicle standards were more stringent than the federal standards. The impetus for the insertion of federal authority into what had been a concern of the states came in part from the nascent environmental movement (the first Earth Day was held in 1970), but also from the vehicle manufacturers themselves. Manufacturers were not in favor of more stringent emission regulation—far from it—but they feared even more a patchwork of disparate and possibly contradictory emission regulations from the states, which, in a national industry enjoying significant economies of scale, might severely complicate vehicle design and production decisions. So manufacturers supported federal regulations, but then sparred with Congress and the EPA over their stringency and scheduling. The ensuing emission standards required two-way catalysts (to control CO and VOCs) by 1979 and three-way catalysts by 1983 .

\footnotetext{
${ }^{3}$ Including the National Environmental Policy Act (1969), the Clean Air Act of 1970, the Federal Water Pollution Control Act Amendments of 1972, the TOSCA, CERCLA, RCRA.
} 
California continued to be a trendsetter, developing new "Low Emission Vehicle" (LEV) standards that went into effect in 1990.The LEV standards were considerably tighter than the then-current California Standards. They also introduced some flexibility by allowing manufacturers to meet a fleet average standard, rather than requiring each vehicle to meet the same standard. The federal government followed suit shortly thereafter. In 1991 the new Clean Air Amendments put in place "Tier 1" standards, equivalent to the California LEV standards, that came into effect active in 1994, followed by Tier 2 standards, for which implementation began in 2004. Tier 2 coupled very stringent emission standards with new ultra-low-sulfur fuel standards that was required in order for the emission control systems to operate properly. Vehicles are placed in "bins" according to emissions. A certain percentage of each manufacturer's vehicles is supposed to be in each bin, and each year the percentages in the more stringent bins increase until implementation is complete in 2009.

However, there was another part of the California LEV program that was not so successful: the Zero Emission Vehicle (ZEV), vehicles without tailpipe or evaporative emissions- a requirement that at the time could only be met by $100 \%$-electric vehicles (EVs). The ZEV mandate required of each major manufacturer a $2 \%$ ZEV fleet penetration by $1998,5 \%$ by 2001 and $10 \%$ by 2003 . It was an attempt to force the development of battery and electric vehicle technology and, it was hoped, make EVs widely available. To meet the volume requirements, it was anticipated that manufacturers that the high initial cost of ZEVs would be subsidized by all other vehicles until innovation and economies of scale brought down the price. However the increase in the cost estimates was so dramatic that this became impossible-from a 1990 estimate of $\$ 1350$ per vehicle by 2000 to $\$ 5,000$ - $\$ 10,000$ in 1995 to an estimate made in 2000 for 2003 vehicles of $\$ 20,000$ per vehicle (NAS 2006). Throughout the period CARB was watering down the program, not only the fleet requirements but by introducing the concept of a "partial ZEV" that did not have zero emissions. The program lapsed when it became evident that the battery technology had not progressed nearly fast enough to make the electric vehicle a viable commercial alternative.

California's LEV program has been a major influence on the federal emission standards. The LEV itself led to the development of emission technology that was more durable and robust and that allowed drastic reductions in new vehicle emissions at modest cost, and its success led to the federal promulgation of similarly stringent standards. The ZEV experience, however, had a less happy outcome. While it did advance technology in some areas, it failed in its stated purpose and what technical advances it did achieve came at high cost to manufacturers. It should be noted that despite the failure of the ZEV, California's LEV program is an example of one of the chief advantages of federal systems like the U.S. and EU, first pointed out by Justice Brandeis of the U.S. Supreme Court: "It is one of the happy incidents of the federal system that a single courageous State may, if its citizens choose, serve as a laboratory; and try novel social and economic experiments without risk to the rest of the country." (1932)

Warranties. Along with emission standards, EPA regulations also extended the mandatory warranty on emission control systems (ECS). In the early 80s there were no special requirements on the warranties on the ECS, and they were no longer than the warranties on other parts or systems. Since 1995, however, the minimum warranty has been 24 months or 24,000 miles, and specified major ECS parts-catalytic converters, electronic emissions control units and onboard diagnostic devices-have a warranty of 8 years or 80,000 miles. 
Better technology and, perhaps, better warranties have made ECS much more reliable and durable, and the improvement can be seen in the trends in emissions from same-aged used vehicles at different times. Figure $\mathrm{xx}$ below shows the average hydrocarbon emissions in grams per mile as a function of vehicle age. The data are required emission test data taken from the vehicle Inspection and Maintenance (I/M) program in Arizona in the 1990, 1995 and 1992. Previous work (Harrington 1997) had shown that emissions from vehicles with poorer fuel economy tend to deteriorate more quickly, so emissions are shown for $20 \mathrm{mpg}(0.1181 \mathrm{~km} / \mathrm{l})$ and $30 \mathrm{mpg}(0.0787 \mathrm{~km} / \mathrm{l})$ vehicles. As shown, vehicles of the same age have much lower emissions in the newer vintages. Also note that the role played by fuel economy in emission deterioration, strong in 1990 and 1995, has disappeared in 2002. Similar results obtain for CO and NOx; see Parry et al. (2005).

\section{Figure 1}

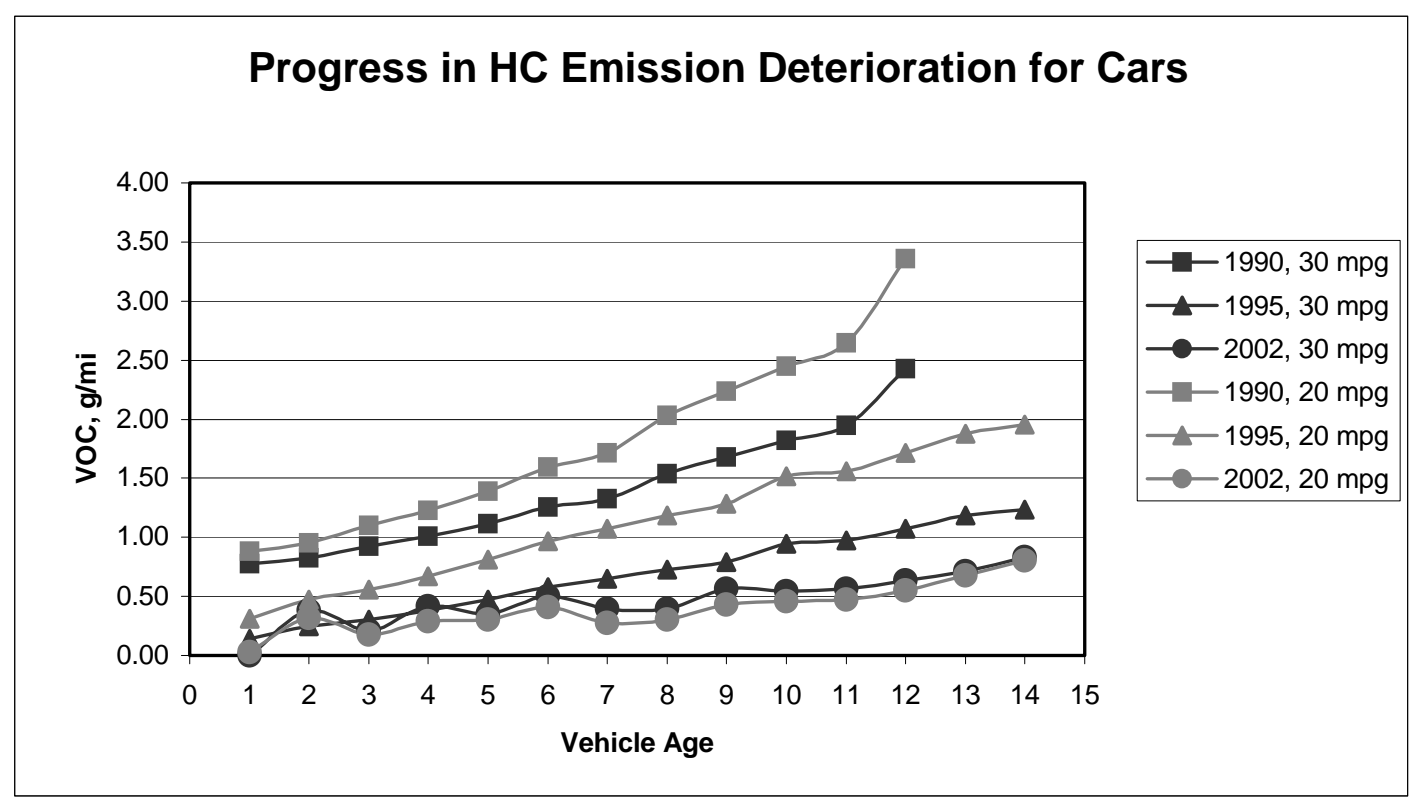

\section{Local emission policies: Europe}

The modern environmental movement and the regulatory responses to it arrived in Europe at about the same time as in the U.S., but regulation of vehicle emissions was slower to develop. Before the European Union existed in its current legal framework, the European Commission exercised more of a convening function than a regulatory function in the development of vehicle emission regulations. Regulations were adopted one country at a time, and there was wide variation among member countries. By 1990, over 98 percent of new gasoline vehicles sold in Germany and the Netherlands had three-way catalysts, while comparable figures in France, Italy and the UK were 3.2, 0.7, and 3.9 percent, respectively. In addition, the adoption of catalyst technology was relatively slow. In developed countries outside the EC, emission abatement in vehicles was embraced more quickly, including elsewhere in Europe. In Norway, Sweden, Switzerland and Austria, all non-EC countries, 100 percent of new were required to have threeway catalysts in 1990 (Boemer-Christiansen and Weidner 1995). In the U.S., as noted above, all new vehicles had three-way catalysts by 1983 . 
There were at least two reasons for the relatively slow response compared to the U.S. and Japan. First, there was a very different perception of the most serious pollution problems. In the U.S. ground-level ozone was seen as the greatest health threat among air pollutants, and tackling ozone demanded reductions in volatile organic compounds (VOCs) and oxides of nitrogen (NOx). Mobile sources were by far the main anthropogenic source of the former and a major source In Europe, ozone was considered a less urgent problem, perhaps on account of the lower frequency of hot, muggy "ozone" days in Europe. Europe, and Germany in particular, was more focused on the ecological effects of acid deposition, concerns that turned their attentions to stationary source emissions of $\mathrm{SO}_{2}$, NOx, and particulates. Not surprisingly, significant reduction in acid rain precursors occurred in Europe as much as a decade before the U.S. Within Europe, though, control of vehicle emissions tended to be pursued in those countries concerned about acid deposition and not in countries that were not. The UK in particular was usually upwind of major continental sources and receptors, and may have perceived lower benefits and greater costs than most other countries from any European-wide regulation of motor vehicle emissions.

In addition, there was a disagreement between Germany and the UK, over the stringency of the standards and whether end-of-pipe abatement technology would be required. Germany favored more stringent standards requiring catalytic converters, but Britain supported a more lenient "lean burn" technology that did not have the fuel economy penalty associated with converters. To get low NOx emissions with the engines then available, the air-fuel mix had to be so lean that the engine suffered from reduced power, misfires and high $\mathrm{HC}$ emissions (Boemer-Christiansen and Weidner 1995 p. 40). Technology developments seemed to favor the use of catalytic converters, in other words.

Nonetheless, there was a European agreement on vehicle emissions in 1991, and an EC directive issued in that year specified emission reductions requiring three-way catalysts for all new vehicles beginning in 1993. These were the Euro 1 standards, and since there have been a steady succession of tighter emission regulations for both gasoline and diesel vehicles, culminating in Euro 4, which went into effect in 2005 and Euro 5, which will be fully implemented in 2009. It is difficult to compare U.S. and EU standards-different emission test cycles, different pollutants or pollutant definitions in some cases, but apparently by the end of the decade the U.S. and EU standards will be approximately the same.

Figure 2 below compares the relative change in total estimated U.S. NOx emissions with those in the UK from 1970 to 2002. The figure reflects the regulatory history, with U.S. emissions declining slowly from their 1970 total throughout the period, with moderate reductions in emission rates being offset by the substantial growth in the passenger car fleet and in annual vehicle use over those years. In the UK, on the other hand, emissions grew much more rapidly between 1970 and 1990, then fell much more sharply as the EU emission regulations gradually diffused across the fleet. 
Figure 2

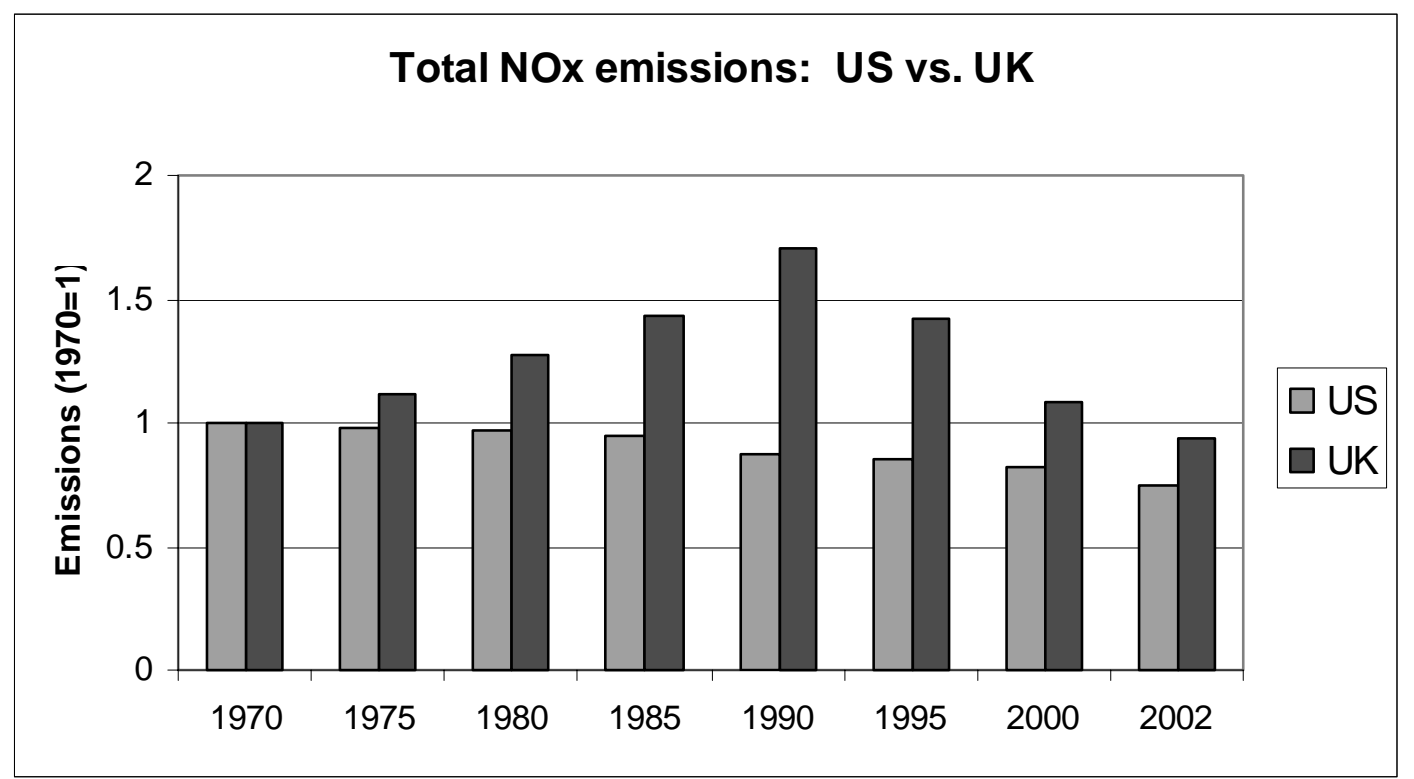

4. GLOBAL EMISSIONS

Growing concern about global climate change has directed the attention of policymakers and analysts worldwide to all major sources of greenhouse gases (GHG). The transportation sector is one such source, and within this sector motor vehicles are now coming under particularly careful scrutiny. In the United States, which leads the world in motor vehicle use both in total and per capita, motor vehicles account for about $20 \%$ of $\mathrm{CO}_{2}$ emissions. In other countries motor vehicle use is growing rapidly, especially in the developing world. Accordingly, the search is on for efficient and equitable policies to reduce emissions of greenhouse gases from motor vehicles. Reducing $\mathrm{CO}_{2}$ emissions essentially means reducing fossil fuel use in vehicles, and there are only three ways to do that:

(i) Reduce the amount of vehicular travel.

(ii) Switch to alternative fuels with lower greenhouse gas emissions.

(iii) Improve fuel economy in vehicles.

For the most part, the policy proposals to address the issue have been limited to (ii) and (iii). Thus the U.S. has had fuel economy standards for new light-duty vehicles since the worldwide oil crisis in 1979 and, after a long period of stasis, has enacted legislation to raise them significantly. And Europe has had a voluntary fuel economy program for manufacturers in place for about a decade and is now proposing to make it mandatory. In addition, on both sides of the Atlantic efforts are underway to use public funds to jump-start a large alternative fuels industry. In the U.S. this has taken the form of large subsidies to fund both pilot and commercial-size plants to produce ethanol. 
These policy initiatives have proceeded even though a comprehensive policy, attacking all margins on which fuel consumption can be reduced, is technically feasible and economically attractive. The availability of such a policy is very different from the case of local emissions, where, as noted above, an efficient policy was not feasible because there was no way to measure emissions of vehicles in use. For global emissions, however, such a efficient policy is feasible, and in fact something close to it in form is already in use in almost every country in the world. The relevant price instrument is a fuel tax. Nearly all the carbon in gasoline is emitted as $\mathrm{CO}_{2}$, and most of the rest is emitted as carbon monoxide $(\mathrm{CO})$, an even more potent greenhouse gas. This, together with the fact that the location and timing of greenhouse gas emissions do not matter, means that a tax on the carbon content of fuel would be an almost ideal instrument against global warming - "almost" because an ideal instrument would set the tax rate equal to the marginal damages in Table 2. A tax with this property is called a Pigouvian tax.

The familiar gasoline tax, which is in use in nearly every country, could be easily converted to a carbon tax, and even the relatively low fuel taxes in the U.S. (which average about 40\&/gallon) would exceed the marginal damages of carbon emissions reported in Table 2. However, in many countries, including the U.S., fuel taxes are earmarked for road construction. There is a rather arcane argument among economists whether fuel taxes could be considered a Pigouvian tax under these circumstances, depending on whether one believes the amount of roadbuilding is truly contingent on the tax revenues. If it is, then the tax revenues cannot be said to be internalizing the externality, since they are used up in the provision of infrastructure. In most European countries the issue is moot, inasmuch as fuel tax revenues are much higher than required for transport and make a substantial contribution to the general fund. European fuel taxes, it seems safe to say, are a true Pigouvian or even supra-Pigouvian tax. That is, according to the estimates of external damages of driving presented above, most Europeans are already internalizing the carbon externality.

Of course, the global warming debate is not being driven by estimates of damages in either Europe nor North America. Steps are already being taken in Europe to improve vehicle fuel economy directly, perhaps by direct standards on fuel economy as in the U.S. If policy-makers and the public want larger reductions in fuel use than Europe's high taxes currently bring about, it could be because of concerns about oil dependency, although as noted in Table 1 those externalities are not very large either. Perhaps the answer is that the estimates are lacking credibility, or perhaps that what people are really worried about is not the mean but the extremes of the value distribution.

There is one other possible explanation for the preference for fuel economy standards rather than fuel taxes, and that is skepticism about whether the "market" for fuel economy really works. One of the most persistent and effective skeptics is David Greene of the Oak Ridge National Laboratory in the U.S., and in recent testimony before Congress he explains why. First, surveys of new car buyers suggest that they are willing to pay for no more than 2-3 years of fuel economy improvements. In addition, manufacturers believe that consumers have at most a 3-year horizon for fuel economy improvements, and they design their vehicles accordingly. Third, even if consumers wanted to value fuel economy properly, it is not that easy to do so. A vehicle is a bundle of attributes that consumers value - fuel economy, reliability, power, legroom, etc.- - and consumers are rarely presented with choices that hold all the other attributes except fuel economy constant, so that consumers can easily see what fuel economy "costs." 
On the other hand, econometric studies of consumers' purchase decisions for new vehicles consistently show that the implied willingness to pay for fuel economy is at least equal to what can be justified by the lifetime fuel savings. The most recent and one of the most sophisticated study with such findings is Train and Winston (forthcoming). More research is needed to resolve this apparent anomaly between what consumers say and what they actually do.

\begin{tabular}{|l|c|c|c|c|}
\hline \multicolumn{5}{|c|}{ Table 3} \\
Statistics on vehicle and fuel use, U.S. and EU (EU-15) \\
\hline
\end{tabular}

Some trends in vehicle ownership and use are shown in Table 3. Not surprisingly, vehicle ownership in the U.S. far exceeds that in Europe, but the EU's car fleet is growing faster. This is consistent with the Dargay et al. model described above. Fuel economy in the EU is much better, but it is rather a surprise to find the use per vehicle to be slightly higher in Europe. (This will bear some further looking into to make sure there is no problem here.). Except for this last item, the numbers reflect the somewhat lower incomes and much greater cost of vehicle ownership and use in Europe. It is of particular interest that fuel economy increased substantially in the EU but not the U.S. between 1995 and 2002, presumably a reflection of the higher fuel prices, which exert a constant pressure to improve fuel economy. Despite those higher prices, however, between 1995 and 2002 the increase in vehicles per capita in the EU nearly offset the gains in fuel economy and passenger use per vehicle.

\section{Biofuels}

In the short run, there are few ways to achieve substantial reductions in vehicular fossil fuel use. Exotic new vehicles, such as fuel cell or all-electric vehicles, may eventually be part of the solution, but the technology is not yet developed sufficiently. Greater penetration of more fuelefficient conventional vehicles, such as hybrids or diesel vehicles, can produce fairly quick but limited results, the limit being that they continue to use fossil fuels, just a bit more efficiently than conventional vehicles. The attraction of biofuels is that they require at most modest changes to existing vehicles. In addition, biofuels can, with some exceptions, make use of the existing fuel distribution network.

Both Europe and the United States have made extensive commitments to increasing production of ethanol and biodiesel, the most important biofuels, in the last decade. Biofuels make up a very small share of liquid fuels used in transportation-about $1.3 \%$ in the U.S. and $0.7 \%$ in the EU in 2006-but they are growing rapidly. As shown in Table 4, U.S. ethanol production tripled 
between 2000 and 2006, while biodiesel production, essentially nonexistent in 2000, approached 2 million tonnes in 2006. Corn is the principal feedstock, accounting for over 90 percent of ethanol production. In Europe, hardly any biofuels were produced in 2000; by 2007 production exceeded 10 million tonnes, with planned expansions amounting to an additional 25 million tonnes. The production pattern is the reverse of what is found in the U.S., with biodiesel being by far the dominant fuel. The principal feedstock is rapeseed oil, responsible for more than 90 percent of biodiesel production.

\begin{tabular}{|c|c|c|c|c|}
\hline \multicolumn{5}{|c|}{$\begin{array}{c}\text { Table } 4 \\
\text { Trends in production of biofuels, U.S. and EU } \\
\text { (in million tonnes) }\end{array}$} \\
\hline \multirow[t]{2}{*}{ Year } & \multicolumn{2}{|c|}{ U.S. } & \multicolumn{2}{|c|}{ EU } \\
\hline & Ethanol & Biodiesel & Ethanol & Biodiesel \\
\hline 2000 & 5.25 & 0.007 & 0.2 & 0.7 \\
\hline 2002 & 7.0 & 0.05 & 0.4 & 1 \\
\hline 2005 & 10.9 & 0.25 & 0.8 & 3.2 \\
\hline 2006 & 15.2 & 1.75 & 1.2 & 4.9 \\
\hline 2007 & -- & -- & 2.9 & 8.4 \\
\hline $\begin{array}{l}\text { Additional planned or under } \\
\text { construction }\end{array}$ & & & 7.0 & 16.6 \\
\hline
\end{tabular}

This dramatic increase in biofuels production was produced by the generous use of subsidies. In the U.S. ethanol was first subsidized in 1978 through an output subsidy of $40 \varnothing$ per gallon (at a time when fuel cost about $\$ 1.00-\$ 1.50$ at the pump). From that time until the present, ethanol has continued to enjoy an output subsidy that varied between 40 and $60 \phi / g a l$, and is currently $51 \phi / g a l$. In the meantime the output subsidy has been joined by a plethora of other instruments, including (i) an import duty of $54 \mathrm{c} / \mathrm{gal}$ on ethanol intended for use in transportation, supposed to keep Brazilian cane ethanol out of the U.S. market, (ii) product content rules, mandating a minimum biofuel content, (iii) support for feedstock producers, and (iv) consumption subsidies, such as credits for "clean" vehicles and privileges such as the ability to use HOV lanes. While the federal government was first to subsidize biofuels, individual states followed with their own policies, and today 28 states offer subsidies of various kinds for biofuels (Koplow 2006).

European subsidization of biofuels began around 1992 as a part of the reform of the Common Agricultural Policy (Kutas 2007). Subsidies applied to ethanol and biodiesel equally, but biodiesel production was quicker off the mark, presumably because diesel was an imported item while gasoline was produced in surplus and exported. As in the U.S., action has not been limited to the central government, but individual countries have also enacted their own subsidies. As in the U.S., production in the first decade was modest by today's standards, but took off after around 2002. 


\begin{tabular}{|c|c|c|c|c|}
\hline \multicolumn{5}{|c|}{$\begin{array}{c}\text { Table 5 } \\
\text { Estimated biofuel subsidies, various units }\end{array}$} \\
\hline \multirow{2}{*}{ Total support } & \multicolumn{2}{|c|}{ U.S. } & \multicolumn{2}{|c|}{ EU } \\
\hline & Ethanol $^{\mathrm{a}}$ & Biodiesel $^{\mathrm{a}}$ & Ethanol $^{\mathrm{a}}$ & Biodiesel $^{\mathrm{a}}$ \\
\hline$\$ /$ gal & 1.25 & 1.35 & & \\
\hline$€ /$ liter & 0.23 & 0.24 & 0.74 & 0.50 \\
\hline \$/MM BTU & 14.90 & 11.50 & & \\
\hline$€ / \mathrm{GJ}$ & 9.83 & 7.49 & 35 & 15 \\
\hline \$/gal. fossil equivalent & 1.70 & 1.47 & & \\
\hline$€ /$ liter fossil equivalent & 0.31 & 0.27 & 1.10 & 0.55 \\
\hline Subsidy/market price & $36 \%$ & $49 \$$ & $110 \%$ & $70 \%$ \\
\hline$\$ /$ tonne $\mathrm{CO}_{2}$ equivalent & 545 & NA & $\begin{array}{r}990^{\mathrm{b}} \\
4680^{\mathrm{c}}\end{array}$ & $\begin{array}{c}310^{\mathrm{d}} \\
1008^{\mathrm{d}}\end{array}$ \\
\hline$€ /$ tonne $\mathrm{CO}_{2}$ equivalent & 378 & NA & $\begin{array}{r}687^{\mathrm{b}} \\
3250^{\mathrm{c}}\end{array}$ & $\begin{array}{l}215^{\mathrm{d}} \\
880^{\mathrm{e}}\end{array}$ \\
\hline \multicolumn{5}{|c|}{$\begin{array}{l}\text { Sources: Koplow (2006), Kutas et al. (2007) } \\
\text { Notes: a. Exchange rate: } € 1.00=\$ 1.44 \\
\text { b. sugarbeet feedstock } \\
\text { c. grain feedstocks } \\
\text { d. used cooking oil feedstocks } \\
\text { e. canola oil feedstocks }\end{array}$} \\
\hline
\end{tabular}

The Global Subsidies Initiative has made an attempt to aggregate all the multifarious subsidies that benefit biofuels for the countries that are important biofuels producers. Table 5 uses data from the reports for the U.S. and EU and displays the subsidy intensity, which can be thought of as the amount by which the subsidy distorts the various markets affected. The authors of these reports calculate, in each case, at least two scenarios based on different assumptions. With one exception the numbers in Table 5 reflect the midpoint of those scenario estimates. That exception is U.S. corn ethanol, for which one of the scenarios generates more $\mathrm{CO}_{2}$ than is generated by the amount of oil it displaces. The figure in the table represents the other scenario only. In the U.S. case, the authors also make a rough calculation for cellulosic ethanol, which has a cost per $\mathrm{CO}_{2}$ equivalent of about $\$ 150$, but that estimate is rather suspect since there is no commercial production of cellulosic ethanol yet. In addition, in the U.S. report it proved impossible to find data to construct an estimate for biodiesel.

All the measures in Table 5 suggest that biofuels production is costly and not very efficient, but perhaps none more so than the cost-effectiveness of carbon reduction. Even the Stern (2006) Review, which puts damages from future warming at5-20 percent of world GDP, has a current social cost estimate of $\$ 311$ per ton, which is dwarfed by most of the estimates in Table 5, especially the European estimates.

\section{CAFE}

In the United States, gasoline taxation to mitigate global warming has very little purchase with politicians, and little wonder, considering how unpopular gas taxes are with the general public. 
These taxes are widely perceived as unfair to the poor and to those whose circumstances and life choices have locked them into a high-mileage lifestyle. And their effectiveness is challenged, not only by the public but also by some economists, who argue that the low price elasticity of motor fuel will require very large tax increases to have the desired effect (e.g., Greene 1991). Indeed, recent studies find the elasticity of motor fuel to be lower than ever, perhaps a reflection of the low relative price of fuel, at least until recently (Small and Van Dender 2005).

Instead, the favored approach is likely to be mandated fuel economy standards for new vehicles powered by fossil fuels. Since 1979 motor vehicles in the U.S. have been subject to fleet-weighted corporate average fuel economy (CAFE) standards. At the time of enactment the principal justification was a concern about a scarcity of motor fuel and fear of a reliance on imported oil. Today these concerns have abated somewhat, but the policy is still strongly favored by environmentalists as a way of curbing emissions of greenhouse gases. From 1991 to 2005 the CAFE standards have required fuel economy in new cars and light trucks to be 27.5 and $20.7 \mathrm{mpg}$ $(0.087$ and $0.114 \mathrm{l} / \mathrm{km})$, respectively. In 2005 , the standard for light trucks was raised about 10 percent, to be implemented between 2008 and 2011. In addition to raising the standard, the National Highway Traffic Safety Administration (NHTSA), the government agency responsible for the CAFE standards, introduced a new approach to CAFE that was significantly different to the old CAFE in several ways, which we discuss further below. And in December 2007, after many years of effort, Congress passed legislation to raise the CAFE standards to $35 \mathrm{mpg}$ (0.676 $1 / \mathrm{km})$, to be achieved by 2020 .

Because CAFE stands out as the principal alternative policy to higher fuel prices to control greenhouse gas emissions in the transport sector, and because it offers so many examples of the unintended consequences of policies, it will be the focus of the discussion below.

Between 1978 and 1991 the CAFE standards increased from 18 to $27.5 \mathrm{mpg}$ for cars and from 17.2 (in 1979) to $20.7 \mathrm{mpg}$ for trucks. Over that same period, the fuel economy of new vehicles sold in the United States increased from 19.9 to 25.1 (U.S. DOE 2000). Most observers agree that this increase was caused by CAFE (NRC 2002), and a recent econometric study of vehicle fuel use by state found CAFE to have had a strong effect on fuel economy (Small and Van Dender 2006). One of the points of contention is the "rebound effect," which prevents an increase in fuel economy from causing a proportional decrease in fuel use. The size of the rebound effect has steadily fallen along with the elasticity of travel with respect to fuel price. Small and Van Dender (2006) found the long run rebound effect to be 0.22 , and when they allow it to vary over time, they find that in the most recent period it falls to 0.12 . The rebound effect is real but fairly small.

There is less consensus concerning other effects of CAFE, including its effect on highway safety and its role in several profound changes in the U.S. motor vehicle market since 1980. These controversies are due partly to problems inherent in fuel economy standards in general, and partly to the details of the particular CAFE standards adopted.

\section{Details of CAFE Policy}

CAFE established separate standards for cars and light trucks, and the timetable of gradually increasing car standards was specified in the legislation itself. For trucks, standards were established later by regulation. At the time, most trucks were commercial and farm vehicles, and business and agricultural groups argued successfully that severe restrictions would adversely 
affect profits and productivity. Federal policy also favored light trucks by exempting vehicles exceeding 8,500 pounds from any CAFE standards and by exempting trucks from the "gas guzzler" tax imposed on cars. The upshot was that the CAFE standards for trucks were much more lenient—and remain so today.

The difference between car and truck standards was rendered especially important by another aspect of the CAFE policy, little noticed at the time: the definition of car and light truck. Manufacturers managed to get trucks defined in a very liberal way, such that a vehicle was considered a truck if it had no hump behind the front seat and if its rear seats could be removed without the use of tools.

The fuel economy standards were also "fleet-weighted" by manufacturer. This approach allowed manufacturers much more flexibility than a set of model-specific standards and hence lowered the costs of meeting a particular fuel economy standard. Thus a manufacturer could still sell gas guzzlers as long as their sales were offset by sales of enough subcompacts that the average fuel economy met the standards. To prevent manufacturers form shifting production (and employment) abroad, where small-vehicle capacity and expertise were high, a manufacturer's imports (from outside North America) were considered separately from domestic production.

Several writers have pointed out that the CAFE policy, in principle at least, creates some unusual and even perverse incentives. Vehicle manufacturers have three general strategies for meeting the CAFE standards: (i) adopt fuel-saving innovations in new vehicles, (ii) modify vehicle characteristics to reduce fuel use (mainly, reduce vehicle weight), and (iii) use pricing to affect the mix of vehicles sold. That is, a manufacturer can improve its CAFE rating by raising the price of big cars and lowering the price of small cars. This third alternative was not much discussed during the legislative deliberations over CAFE, but it is the only alternative available in the short run. Such a fleet-mix strategy would affect not only the mix of vehicles but also the number of vehicles sold, and if sales increased, then aggregate fuel use would rise even as average fuel economy improved. In the event, however, this possibility proved to be more hypothetical than real, but it is a possibility.

A more serious market structure question involve cars and light trucks. Between 1980 and 1998, sales of new light-duty vehicles that were classified as trucks increased from 21.4 to $47.3 \%$. Part of the growth could be attributed to the growing popularity of pickup trucks in both commercial and household applications. But far more important was the introduction of minivans and sport utility vehicles (SUVs), new families of vehicles that were classified as trucks for regulatory purposes but had many of the characteristics and appeal of passenger cars. By 1990 what had been only a farm or commercial vehicle had become a household vehicle as well.

The growth of the light truck market is a fact; the role of CAFE in that growth is less certain. The disparity between car and light truck CAFE standards is certainly a strong incentive for manufacturers to look for ways to sell trucks to car buyers, and the loose definition of a truck certainly created opportunities to do that. However, other events were occurring simultaneously. As the recent NRC report points out, during the 1980s the full-size light-duty truck category was dominated by domestic U.S. manufacturers, and they naturally sought to expand sales in that category. 
CAFE policy has also suffered from a lack of policy coordination in the matter of giving credits to vehicles that use alternative fuels. Several manufacturers have developed "flex-fuel" vehicles, which are capable of running on either gasoline or $85 \%$ ethanol (E85). To encourage the further production of these vehicles, there is a section of the CAFE regulations that allows such vehicles to be treated very leniently by CAFE policy. Essentially, for determining fuel economy of such vehicles, a large fraction of fuel is assumed to be renewable and not counted in the fuel economy calculation, giving these vehicles very impressive fuel economy ratings. This provision was supposed to have been accompanied by an E85 subsidy to ensure that its price at the pump was less than that of gasoline. However, that subsidy was delayed getting out of Congress, so for a long time after these vehicles were introduced, supplies of E85 were difficult to find and were in any case more expensive than gasoline. The result was that these flex-fuel vehicles burned gasoline almost exclusively, a very perverse outcome.

\section{CAFE and Highway Safety}

Probably the most important and controversial issue involving CAFE is its putative effect on highway safety, an issue discussed at length by two National Research Council reports (NRC 2002, 1992). The mechanism is weight. Numerous studies, reviewed in both reports, have found a significant negative correlation between vehicle weight and the probability that an accident will result in serious injury or death. Crandall and Graham (1989) connected these results to CAFE in a quantitative way. They estimated that CAFE reduced vehicle weights by an average of $18 \%$, or about 500 pounds. A 500-pound reduction in average vehicle weight was estimated to cause a 14 to $27 \%$ increase in occupants' fatality risk.

There was and still is some controversy at this point about whether it was vehicle weight that was actually protecting occupants. Weight is highly correlated with vehicle length and volume, and it could be that those variables could be the critical ones. Both are plausible, as two different physical principles are at work. When two vehicles of different weights collide head-on, the deceleration is proportionately lower in the heavier vehicle. ${ }^{4}$ Deceleration is also lower in larger vehicles because the greater volume provides greater "crush space"-the ability of vehicle components to absorb the energy of impact and not transmit it to the driver. The simple physics implies that (i) in one-vehicle collisions mass doesn't matter but crush space does, and (ii) in multivehicle collisions it is not mass per se but the disparity in the masses of the vehicles that kills.

The realization that weight disparity was important gave new significance to the observed shift in fleet composition toward trucks. Whereas vehicle safety studies had hitherto concentrated on the safety of the occupants of the vehicle, concern was growing over the fate of occupants of the other vehicle in a crash. The recognition of this externality, together with the controversial article by Crandall and Graham, motivated new work by the National Highway Traffic and Safety Administration on the question (NHTSA 1997). In this study, the effects of weight on accident severity were categorized by vehicle type. A 100-pound weight reduction increased fatalities by about the same amount for cars and trucks (actually, slightly more for trucks) in accidents involving stationary objects, a confirmation of intuition. A 100-pound reduction in car weight

\footnotetext{
${ }^{4}$ Conservation of momentum requires that if, for example, two vehicles, one twice the mass of the other, collide headon while traveling $45 \mathrm{mph}$, the velocity immediately after the crash will be $15 \mathrm{mph}$ in the direction traveled by the heavier vehicle. Thus the change in velocity in the heavier vehicle is $30 \mathrm{mph}$; in the lighter, $60 \mathrm{mph}$.
} 
increased the fatality risk by $2.63 \%$ in a collision with a light truck. However, a similar reduction in trucks reduces fatality risk by $1.39 \%$ in a collision with a car. Taking all types of accidents and their incidence into account, the study found that reducing car weight increases fatality risk by $1.13 \%$ per 100 pounds, while reducing truck weight reduces fatality risk by $0.26 \%$ per 100 pounds. These results remain controversial, and NRC was not able to achieve unanimity on this point.

In its discussions of safety, the NRC committee considered only the effects of differences in weight. But the rebound effect also has obvious safety implications. Indeed, the rebound effect may look small when only fuel consumption is considered, but once its effects on conventional pollutants, accidents, and traffic congestion are brought into the discussion, its effects might not look so small any more.

Finally, It should be kept in mind that CAFE also can affect highway safety through the rebound effect. This effect depends on the assumption, which seems reasonable, that the risk of having an accident increases with mileage driven.

\section{CAFE innovations}

The new CAFE rules introduced by NHTSA in 2005 depart from the existing structure of CAFE in at least two significant ways. First, an effort is made to reduce the incentive for manufacturers to adopt a strategy of weight reduction to meet CAFE standards. NHTSA developed an "attribute" standard, in which a vehicle's CAFE target was determined by a function of a particular vehicle attribute. In this case, the attribute was the "footprint," essentially the area of the rectangle made by the tires.

The second innovation arose in the particular way the attribute function was developed. NHTSA took a large collection of fuel economy technologies, many of which had been examined for cost and fuel economy improvement by the National Research Council (NAS 2002). For each vehicle model it added the technologies one by one until the marginal benefits of raising fuel economy, in terms of fuel savings, equaled the marginal cost of further reductions. This procedure associated with each vehicle's footprint a fuel economy rating. Having done this for each vehicle, they fit a curve through the points to get their function, which related fuel economy to the footprint. In other words, the footprint function embodied an explicit notion of weighing marginal benefits against marginal costs. As far as I know, this is the first time in American regulatory experience that regulators made use of benefit-cost analysis during the design of a regulation, rather than tacking it on at the end.

Target fuel economy ratings were thus assigned to each vehicle model of each manufacturer. Taking a sales-weighted average of the fuel economy targets of all vehicles generated a specific fuel economy target for each manufacturer, tailored to its unique fleet structure. These individualized targets are the CAFE standards that each manufacturer has to meet.

Several rationales, some stated and others unstated, were offered for NHTSA's development of the new attribute standard. The first was a desire to elicit improvement in fuel economy from some manufacturers, chiefly Asian, that hitherto have had to do little to meet the CAFE standards. In addition, the footprint-based attribute standard would reduce manufacturers' incentive to meet the CAFE standards by downweighting and thereby raising the risk of more severe injuries in 
accidents. The RIA contained an extensive discussion of the recent data on the accident outcomes when one vehicle is considerably heavier than the other, concluding that the disparity of weights was an issue only if the heavier vehicle exceed 5,000 lbs. It also took note of the questions that some had raised concerning whether the accident risk was related to weight or size. By choosing footprint, NHTSA was attempting to prevent size reduction from being a compliance strategy. While size and weight are highly correlated, they are not perfectly so, and manufacturers still retained the option of reducing weight if the core size was unchanged.

One other possible if unstated rationale is a concern about the effect of CAFE on American manufacturers. The market strengths of Ford, GM and Chrysler are in larger vehicles, just the ones that would be facing the largest potential change from a CAFE standard of the old structure. These companies have suffered substantial losses of market share in the past few years and still face serious disadvantages in the market because of pension and healthcare requirements for older and retired workers. Thus the new attribute standard may have had a political purpose along with its other objectives.

Finally, although the algorithm incorporated BCA in a clever way, its procedure was not without limitations. For one thing, NHTSA has subsequently faced (and lost) a legal challenge to this procedure, because the only benefit considered was the motorist's fuel costs. The court ruled that in addition the effects on global climate change have to be considered. The second limitation is that the costs that are considered are the cost estimates made prior to promulgation. Actual costs could be very different. In fact, as discussed in the next section it is most likely that they will be lower.

\section{Fuel economy policies in Europe}

In 1998 the EC negotiated a voluntary agreement with the European Automobile Manufacturers Association (ACEA) obligating its members to reduce $\mathrm{CO}_{2}$ emission rates of vehicles sold in Europe (An and Sauer 2004). The goal was an industry-wide average $\mathrm{CO}_{2}$ emission rate of $170 \mathrm{~g}$ $\mathrm{CO}_{2} / \mathrm{km}$ by 2003 and $140 \mathrm{~g} \mathrm{CO}_{2}(39.5 \mathrm{mpg})$ by 2008 . With one year to go, emissions among European vehicles now average about $160 \mathrm{~g} \mathrm{CO}_{2} / \mathrm{km}(34.6 \mathrm{mpg})$, a rate of improvement of about $1.5 \%$ per year, half the $3 \%$ per year that would have been required to meet the 2008 target (Economist.com "Collision Course," December 19, 2007). It is now clear that the voluntary standard is not going to be met in 2008, and in response the EC has proposed a new mandatory target of $130 \mathrm{~g} \mathrm{CO}_{2} / \mathrm{km}(42 \mathrm{mpg}$ ) with a deadline of 2008. According to the Economist, this proposal has split the European car industry. Manufacturers of primarily small vehicles, such as Renault and Fiat, are not too concerned, as their vehicle fleets now average around $145 \mathrm{~g} \mathrm{CO}_{2} / \mathrm{km}$, already within striking distance of the new standard. German manufacturers, especially those that cater to the luxury market, are the most threatened by the new rules. 


\section{THE COST OF FUEL-ECONOMY STANDARDS: PROBLEMS OF OBSERVATION}

There is a great deal of interest now in increasing vehicular fuel economy standards in both the United States and Europe. Analysis of new standards, including the preparation of cost estimates, has become a cottage industry. Three such estimates are reproduced in Figure 3. The first was produced by a committee of the National Academy of Sciences (U.S.) for their 2002 study of improved fuel economy. The NAS generated cost estimates for ten different vehicle types by applying particular fuel-saving technologies to those types. These estimates were converted to quadratic cost functions in Fischer et al. (2004). What is presented is the estimate, converted to euros (in 2007 purchasing power) and carbon intensity, for a midsized vehicle in the American market. The other two estimates represent the average vehicle in the UK fleet. They were produced by the European consultancies Ricardo and TNO and used in the development and assessment of the United Kingdom's energy strategy (DTI 2007)

It is remarkable how closely the NAS estimate, once converted, matches up with the other two, especially the estimate by TNO, and especially when one considers that the NAS estimate was an extrapolation far beyond existing U.S. fuel economy ratings in 2002 (or today, for that matter).. That is perhaps due to a fortuitous choice of assumptions in converting the U.S. estimate, or to a lack of change in the cost estimates since 2002, or to an indication of the extent to which analysts are influenced by other analysts.

Figure 3

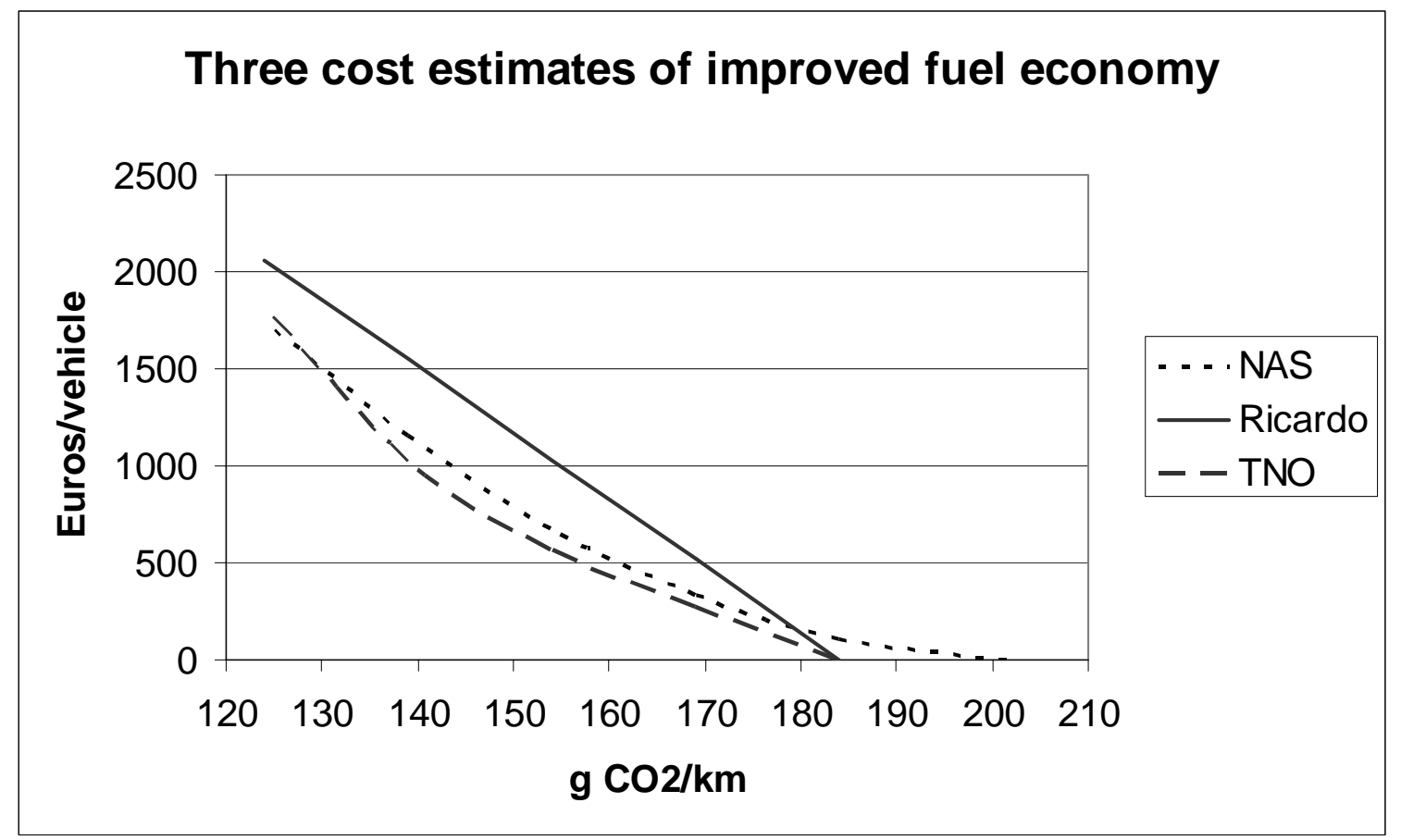


In any case it is worth keeping in mind that these are cost estimates, not actual costs, and therefore subject to error. If cost estimates are used to make regulatory decisions, then errors in those cost estimates could propagate and produce regulations that are less effective and efficient than they might otherwise be. Indeed, studies comparing government estimates of the costs of regulation with actual costs estimated after implementation show that the ex ante estimates tend to overestimate the actual costs. (How different regulation is from government investment projects, especially in infrastructure and defense, for which costs are famously underestimated.) If cost estimates are too high, then it is possible that regulation is not as effective as would be justified. That is particularly true in the case of the U.S. attribute standard, inasmuch as it relies so closely on BCA in the design of the final regulation.

Naturally we have very little experience with the accuracy of estimates of the cost of fuel economy regulations. In Europe, vehicles have not been subject to fuel economy regulations, although the high fuel prices have assured that they would be much more efficient than their American counterparts. In the U.S., there has been no change in fuel economy regulations since 1991, so there has been no occasion for a comparison of ex ante and ex post fuel economy regulations. Nonetheless, it should be possible to use the actual data on fuel economy and other attributes, plus the sticker price for various vehicles and use a regression to estimate the marginal willingness to pay and the marginal cost of each attribute (They are assumed to be equal in equilibrium). However, when researchers have tried to do that, as often as not they have found the cost to be negative. The problem is that one does not observe all combinations of vehicle attributes. Indeed, poor fuel economy is more likely to be found in luxury and high-performance vehicles with higher sticker prices. That is, with the limited set of data found in actual production vehicles, the cost of fuel economy cannot be reliably isolated.

With relatively little actual information on the cost of fuel economy, perhaps some insights are available from studies on local pollution regulations. There is in fact considerable experience with estimating the cost of local pollution abatement technologies, but it offers a mixed message on regulatory cost estimates. Researchers have conducted studies of both vehicles and fuels, and on the whole the latter are much more conclusive. One reason is that in both Europe and the U.S., fuel standards for emission reductions have been applied in some countries or in some metropolitan areas and not others, which means that analysts can observe product prices with and without the regulation. For vehicles, on the other hand, vehicle standards are applied throughout the EU or U.S., so that observation of the incremental effect on vehicle prices is impossible.

As far as I am aware, regulatory cost comparisons are uncommon in Europe, because until recently there were few analyses of the costs of regulation during rulemaking. Requirements for regulatory impact analysis, the engine for driving such analyses in the U.S. since 1981, has only appeared in Europe much more recently. The difficulty is illustrated by a review of the UK air quality strategy (AEA Technology 2004), commissioned by the UK Department for Environment, Food and Rural Affairs (DEFRA) commissioned. The mobile-source section reviewed the vehicle regulations Euro 1,2, 3 and 4, plus a number of fuel quality regulations. Necessarily the authors limited their attention to an ex post analysis conducted in 2001 and to the policies that could have produced significant emission reductions by that date. For vehicles, their analysis was limited to Euro 1. Unfortunately, however, it was impossible for the authors to rely on existing documents for the comparison of vehicle costs. For Euro I technology there was no regulatory impact analysis (RIA) providing an estimate of ex ante costs, while for Euro 2 technology the authors 
were unable to find an existing ex post study. Although an ex ante Euro I estimate could not be found, the authors reported on the cost substituted other information from both European and American sources. The former included industry estimates of $£ 400-£ 600$ per vehicle for catalytic converter technology reported by the Stockholm Environment Institute (SEI 1999) and an estimate of $£ 350$ per vehicle in a report (not cited) commissioned by the UK government. The authors also mentioned that a prominent manufacturer sold catalytic converters to the industry for less than $£ 50$ per unit, but that did not include other components of the ECS or the cost of installation. These Euro 1 estimates were really not very conclusive.

In the U.S. the longer tradition of RIAs provides more ex ante studies to choose from, both for California standards and for federal standards. In California, Cackette (1998) found estimates prepared by industry and California Air Resources Board (CARB) of the cost of California lowemission vehicle (LEV) regulations from the early 1990s. Industry estimates (\$788 per vehicle) greatly exceed CARB estimates ( $\$ 174$ per vehicle), with the latter being a little higher than actual data from 1998. Actual costs were estimated to range from $\$ 75$ to $\$ 152$ for a limited selection of models. It is not clear how the actual cost estimate was calculated. For ultra low emission vehicles (ULEV), Cackette found estimates by individual firms. The GM estimate of this rule was "up to" $\$ 1000$ per vehicle, while the estimate submitted by Honda was only $\$ 300$. CARB's estimates was $\$ 250$.

However, not all estimates of California were overestimates. As noted above, CARB projected cost and availability of the ZEV, but unfortunately the technology has never emerged to allow the vehicles to be produced at reasonable costs.

The most comprehensive ex post assessment of motor vehicle standards and comparison with ex ante estimates was produced by Anderson and Sherwood (2002), who analyzed six fuel regulations and ten vehicle standards. Unlike the fuel regulations, it was impossible to use vehicle price changes to estimate the cost of individual rules. Not only were regulations becoming effective simultaneously with several other vehicle regulations, but many regulations were phased in over a several years. For example, Tier 1 standards for light-duty vehicles were phased in so that 40 percent of vehicles had to comply in 1994, 80 percent by 1995, and 100 percent by 1996 . Instead, AS use the cost estimates to estimate a pattern of expected cumulative cost increases for all vehicles from 1994 to 2001. They compare this trend to the BLS price trends for motor vehicles. They find that by 1996 EPA had overestimated the cumulative cost of the vehicle rules by about $\$ 150$ per vehicle and by 2001 by about $\$ 100$ per vehicle, indicating some minor amount of cost underestimation between 1996 and 2001. AS attribute this outcome not to underestimation of the cost of later regulations, but to changes in the price of precious metals in 1997 and 1998 that affected the cost of catalytic converters required by vehicle emission standards adopted prior to 1996. Correcting for the unanticipated change in precious metals prices, it appears likely that the costs of most of the regulations were overestimated by EPA; nonetheless, for the purposes of the tally below all the vehicle emission regulations enacted during the 1990s will be lumped together and counted as one.

A final and probably needless comment at this point: the estimates from industry sources again were serious overestimates (a cumulative $\$ 500$ per vehicle by 2001) of the actual compliance costs, although most of the error appears attributable to a single regulation, the estimate of the costs of on-board diagnostic systems (OBD) required in 1996. 


\section{FURTHER THOUGHTS ABOUT POLICY}

Above we've reviewed three sets of policies, one to address local pollutant emissions from vehicles and two to address emissions of $\mathrm{CO}_{2}$. Here are some final words about each.

The local pollutant policy is the use of emission standards for new vehicles. This was not the only mobile-source policy put in place over the last 40 years; indeed, to make emission standards work required at least one major change to fuels, and that was the removal of lead from gasoline. Once gasoline was lead-free, however, the fuel standards did achieve by far the greatest part of the emission reductions, and new cars today are very probably 98-99\% cleaner than new cars in 1970. Their emission control systems are also far more robust and durable than ever. The remaining vehicular emission problems are no longer found in light-duty vehicles but in heavy-duty on-road vehicles and non-road vehicles. New regulations have been promulgated to address each, but it is too early to tell how they will do. Another mobile source pollution problem that still resists solution is the problem of maritime emissions. In coastal cities in the U.S. and western Europe, other emission sources have been reduced so much that emissions associated with the port have become one of the main sources of pollutants.

We also considered policies encouraging the replacement of fossil fuels with biofuels in order to reduce $\mathrm{CO}_{2}$ emissions. A wide range of policies has been implemented in the U.S. and EU to further this goal. Some have been pure subsidies of outputs, others subsidies of outputs, and others regulations, say, to require consumption of the biofuels produced. Determining the overall effect of these subsidies is not easy, but some recent work suggests that the cost of forcing these new technologies is very high, and perhaps, in some cases, (U.S. ethanol, notably) they may encourage technologies that produce more $\mathrm{CO}_{2}$ than they displace. If nothing else, these programs demonstrate that the task of reducing fossil fuel use in transportation is extremely arduous. And yet, that task is likely to be necessary if some current fears about the severity and speed of climate change are to be guarded against. The question is whether subsidies, as politically popular as they generally are, is the best way to do that. We hope to discourage use of one fuel by extreme encouragement of another. If it were possible, it would probably make more sense to discourage the use of fossil fuels directly by taxing them rather than subsidizing their competitors. A tax on fossil fuels would automatically encourage the production of those competitors, but it would also encourage other actions that would reduce $\mathrm{CO}_{2}$ emissions, including reducing car use and buying more fuel efficient vehicles. (Or instead of a tax, an alternative would be to bring motor vehicles into the evolving cap and trade program for stationary sources. Probably the best way to bring in vehicles would be to impose and "upstream" cap and trade policy, which would not require individual motorists to trade carbon permits for the privilege of using their vehicles. Permits would be held by refiners who would have to surrender a permit in order to sell a quantity of fuel. As far as the motorist is concerned, it would act like a tax, except that the price of fuel would probably be more variable.) A tax on fossil fuels would also avoid a real danger of the apparently excessive subsidies we see in the U.S. and EU today, and that is to create a community of beneficiaries that will resist any serious change to the policy, even if it becomes obvious that it is not a good idea. Once a thousand biofuel plants are built, encouraged by a web of subsidies out of proportion to the public benefit, there could be major issues of stranded cost that will make policy change very difficult. 
Finally, there is the CAFE policy to improve fuel economy in vehicles. The U.S. has had a mandatory CAFE policy in place for 30 years, and the majority view, I would say, is that it did have some effect in improving overall fuel economy and reducing fuel use in the U.S., not in absolute terms certainly, but compared to what fuel use would have been in the absence of CAFE. There is also broad agreement that to a significant degree the problems of CAFE were not inherent, but were attributable to the particular details of the American policy. In particular, separating vehicles into car and truck groups for averaging purposes might have worked better if it hadn't been rather easy to build vehicles that appealed to households as cars but which were considered trucks for regulatory purposes. The incentive to do this was heightened by the large difference between the car and truck standards. CAFE might also be improved by greater flexibility for manufacturers. Already, CAFE permits fuel economy "trading" within a manufacturer's fleet of vehicles. It might improve the cost effectiveness of the program to allow trading across manufacturers. In addition, what it would certainly do is make the cost of CAFE more transparent, as the price of the CAFE credits would become known. 


\section{REFERENCES}

AEA Technology. 2004. “An Evaluation of the Air Quality Strategy.” Report prepared for DEFRA.

An, Feng and Amanda Sauer. 2004. Comparison of Passenger Vehicle Fuel Economy Standards and GHG Emission Standards Around the World. Pew Center on Global Climate Change.

Anderson, John and Todd Sherwood. 2002. Comparison of EPA and Other Estimates of Mobile Source Rule Costs to Actual Price Changes. SAE 2002-01-1980.

Boemer-Christiansen, Sonja and Helmut Weidner. 1995. The Politics of Reducing Vehicle Emissions in Britain andn Germany. (Madison, N.J.: Fairleigh Dickinson University Press)

Brandeis, Louis. 1932. New State Ice Company v. Liebmann, 285 US 262, 311.

Cackette, Tom. 1998. "The Costs of Emission Controls" Presentation at MIT Workshop on New Vehicle Technology, MIT (June).

Crandall, R.W., and J.D. Graham. 1989. The Effect of Fuel Economy Standards on Automobile Safety. Journal of Law and Economics 32: 97-118.

Dargay, Joyce, Dermot Gately and Martin Sommer. 2007. Vehicle Ownership and Income Growth, Worldwide: 1960-2030. The Energy Journal 28(4).

Department of Trade and Industry (UK). 2007. "Synthesis of the Analysis of the Energy White Paper" (May).

Fischer, Carolyn, Ian Parry and Winston Harrington. 2004. Économic Impacts of Tightening the Corporate Average Fuel Economy (CAFE) Standards," Resources for the Future,

Washington, DC, Report prepared for the Environmental Protection Agency and the National Highway Traffic Safety Administration.

Gomez-Ibanez, J.A. 1997. Estimating Whether Transport Users Pay Their Way: The State of the Art. In D.L. Greene, D.W. Jones, and M.A. Delucchi, eds., The Full Costs and Benefits of Transportation. Heidelberg, Germany: Springer-Verlag Berlin, chapter 3.

Greene, D. 1991. Short-Run Pricing Strategies to Increase Corporate Average Fuel Economy. Economic Inquiry 29(1): 101-14.

Greene, David. 2007. "Policies to Increase Passenger Car and Light Truck Fuel Economy." Testimony before the U.S. Senate Committee on Energy and Natural Resources (January 30). 
Gruenspecht, H. 2001. Zero Emissions Vehicles: A Dirty Little Secret. Resources 142: 7-10.

Washington, DC: Resources for the Future.

Harrington, Morgenstern and Sterner eds. Choosing Regulatory Policy. (Washington: RFF Press).

K.T. Analytics, Inc., and Victoria Transport Policy Institute. 1997. Review of Cost of Driving Studies. Paper prepared for the Metropolitan Washington Council of Governments.

Koplow, Doug. 2006. Biofuels: At what cost? Government support for ethanol and biodiesel in the United States. Global Subsidies Initiative, International Institute for Sustainable Development.

Kutas, Geraldine, Carina Lindberg and Ronald Steenblik. 2007. Biofuels: At what cost? Government support for ethanol and biodiesel in the European Union. Global Subsidies Initiative, International Institute for Sustainable Development.

National Highway Traffic Safety Administration. 1997. Relationship of Vehicle Weight to Fatality and Injury Risk in Model Year 1985-93 Passenger Cars and Light Trucks. NHTSA Summary Report DOT HS 808 569. Springfield, VA: National Technical Information Service.

National Research Council. 2002. Effectiveness and Impact of Corporate Fuel Economy (CAFE) Standards. Washington, DC: National Academy Press.

National Research Council. 2006. State and Federal Standards for Mobile Source Emissions. (Washington: National Academy Press).

Oak Ridge National Laboratory. 2004. Transportation Energy Data Book.

Parry, Ian, Margaret Walls and Winston Harrington. 2007. Motor Vehicle Externalities. Journal of Economic Literature 45(2) (June).

Shore, Joanne. 2005. “The Road Ahead for Light-Duty Vehicle Fuel Demand.” Presented at Energy Information Administration (July).

Small, Kenneth and Kurt Van Dender. 2006. The Effect of Improved Fuel Economy on Vehicle Miles Traveled: Estimating the Rebound Effect Using U.S. State Data, 1966-2001.

Train, Kenneth and Clifford Winston. Forthcoming. "Vehicle Choice Behavior and the Declining Market Share of U.S. Automakers." International Economic Review.

USEPA 2005. U.S. Greenhouse Gas Inventory. EPA-430-R-05-003 (April). 